\title{
THE EFFECT OF RAILWAY ACCESSIBILITY ON THE CHOICE OF UNIVERSITY STUDIES
}

\author{
I. HENKE \\ Department of Civil, Construction and Environmental Engineering, University of Naples, Federico II.
}

ABSTRACT

The choice of university studies is one of the main socio-economic categories that is affected by the quality of public transport services and in particular rail transport. This category is characterized to cover medium to long distances to reach, every day, the place of study. For this reason, among the urban sustainable policies, the mobility choices of the university students have long been analysed in literature. The aim of this paper was to estimate the effect of railway accessibility on the choice of university studies.

The University of Naples Federico II (Italy) is taken as the case study. In the spring of 2014, using the database obtained from the registry office of the university the following were investigated:

- the origin of the daily trips (residential address);

- the trip frequency and the departure/arriving time;

- the modes or sequence of modes used;

- the perceived public transport quality (e.g. travel time, comfort).

To evaluate the catchment area of the university and for analysing what attributes influence the choice of university studies (in particular the 'weight' of a specific railway accessibility), a regression model was used. Among the model attributes educational course variables, home-university distance and a constant-specific attribute were also considered.

The result of the study shows the surprising role of railway accessibility in the choice of university studies; to travel from a station within $900 \mathrm{~m}$ from home is equivalent (in terms of perceived utility) to travel every day a distance greater than $28 \mathrm{~km}$ to reach the university.

Keywords: geographical distribution of students' residences, logistic function, railways stations, transport accessibility.

\section{INTRODUCTION}

Among the urban sustainable policies (e.g. [1-3]), the mobility choices of the university students have long been analysed in literature. This category is characterized to cover medium to long distances every day to reach the university. In many cases the distance between the students' residence and the university, although long, is not encouraging the students to rent a room in a dorm near the university for economic, logistic or cultural reasons. In this case the students choose to travel several kilometres every day to reach the university.

Although much attention has been given by the scientific literature to the accessibility effects on the mobility choices ([4-8]), little attention has been given to the choices of university studies.

In the Italian context, in the recent years, only a few universities (e.g. University of Milan [9, 10]) have carried out a mobility survey to investigate the student transport choice. The results of this study show that the public transport accessibility (in particular railway services) influences the attendance of the students for university activities. For example, from the survey carried out

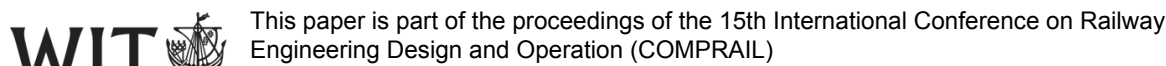

www.witconferences.com
} 
in Milan [9], it appears that the number of students who come from the areas that are served directly by the railway lines is higher. However, in this study, it is not considered if and how much the railway accessibility influences the choice of the students in deciding which university to choose for their education. The choice of the students in deciding which university to enrol is only analysed with respect to the attributes related to the characteristics of the university (e.g. the institute's scientific reputation, curriculum of teachers, infrastructural qualities, etc.) (e.g. [11]) or with respect to possible job opportunities that the university can offer (e.g. [12]). In this study, however, the variables related to the quality and the accessibility of the public transport are not considered while how this variable influences the users' choices is demonstrated (e.g. [13-16]).

Based on these considerations, in this work, the effects of railway accessibility on the choice of university studies are estimated through the following:

a. Quantify the geographical distribution of the students' residences from the technical and scientific departments of the University of Naples (Campania, Italy).

b. Estimate (and so quantify), through a regression method, the weight of a rail service attribute (railway accessibility) in the choice of university studies.

This paper is divided into three parts: in the first section, for the specific case study, the geographic distribution of students' residences is analysed; in the second part, through a logistic regression model, the weight of railway accessibility is quantified. In the last part conclusion and research perspectives are summarized.

\section{CASE STUDY}

The University of Naples Federico II is taken for the case study. This university with more than 150 years of history is one of the oldest and most prestigious universities in Italy. It is placed in the city of Naples (Campania region in southern Italy) (Fig. 1).

In this part of the research, the analysis focused only on the technical and scientific departments of the University of Naples: Architecture, Biology and Biotechnology, Chemistry, Physics, Engineering, Mathematics, Computer Science, Natural Sciences, and Earth Science. All these departments are located in the west of Naples. These departments are served by two metro lines: the Line 2 of Naples that reaches the Garibaldi station, the most important interchange point of the city, and Cumana Line that connects the historical centre of Naples and the northern municipalities. To analyse the geographic distribution of the students' residences, the database available at the registry office of the university was consulted. This database gives information about the residences (address), age and gender of all students. The results show that $71 \%$ of the students reside in the centre of Naples city and in its province (Fig. 2). It is interesting to note that the percentage of students who are not residents in Campania region is negligible. This result is in line with the other Italian universities (e.g. [17]).

Through a geographic information system software, the geographic distribution of students' residence is presented in a territorial map. For clarity of presentation, in Fig. 3, only the main portion of the region (for which $80 \%$ of the university students showed interest) is reported. This area is divided into traffic zones. In Fig. 3, the rate of students (university students for the academic year 2013/2014 among 1,000 inhabitants) for each single traffic zone is shown. It is evident that the distribution of the rate of students is not homogenous; the higher value is in the western part of the territory where the departments analysed are placed. This result would seem to indicate that one of the factors that influences the choice of the university is 'proximity effect'. In other words the distance between the students' residences and the university influences the choice of the university. 


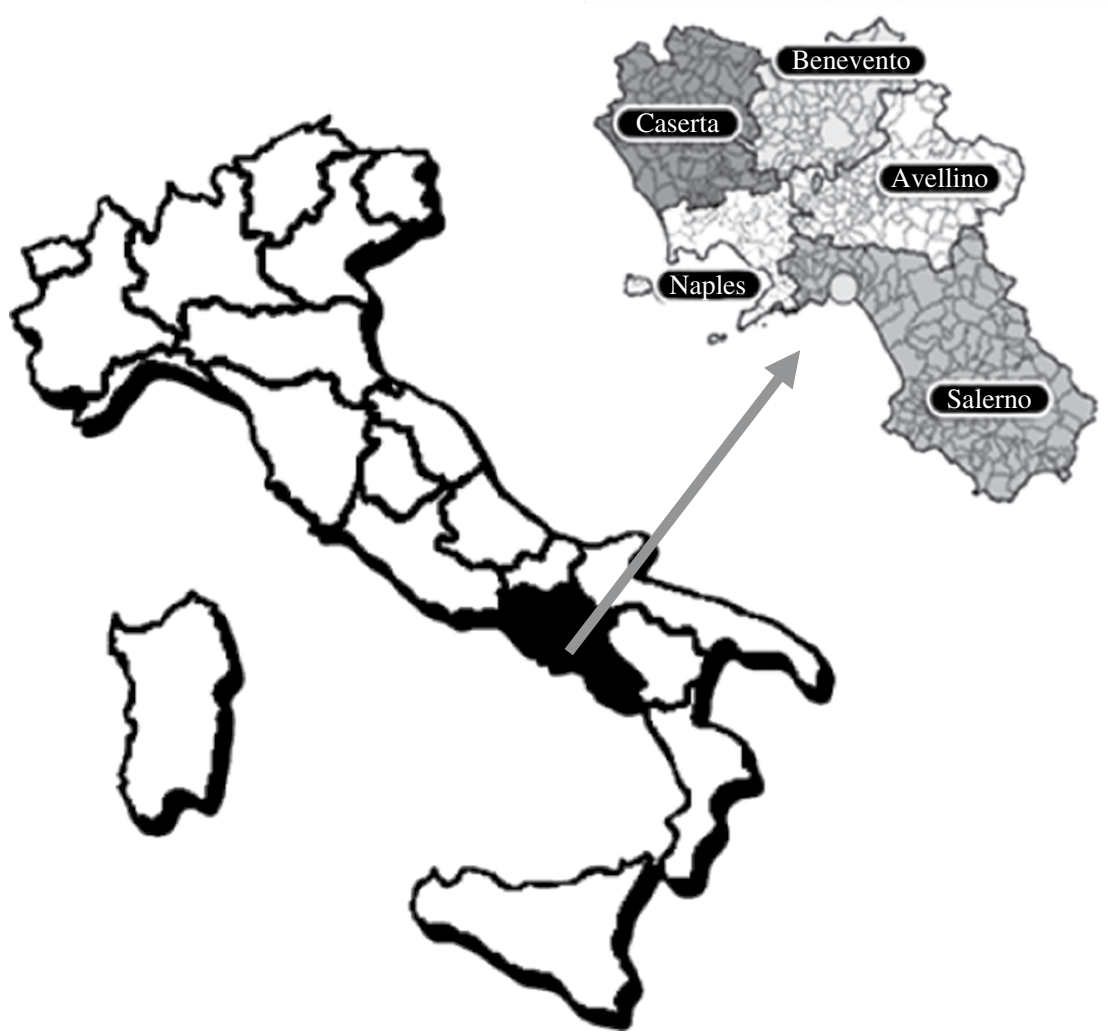

Figure 1: Case study.

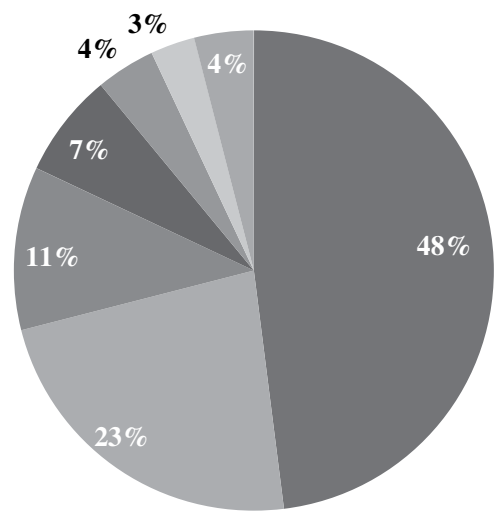
- Province of Naples
- Naples
(without city of Naples)
- Salerno and Province
- Caserta and Province
Benevento and Province
- Avellino and Province
Extra Region

Figure 2: The residence of students of the technical and scientific departments of the University of Naples Federico II. 


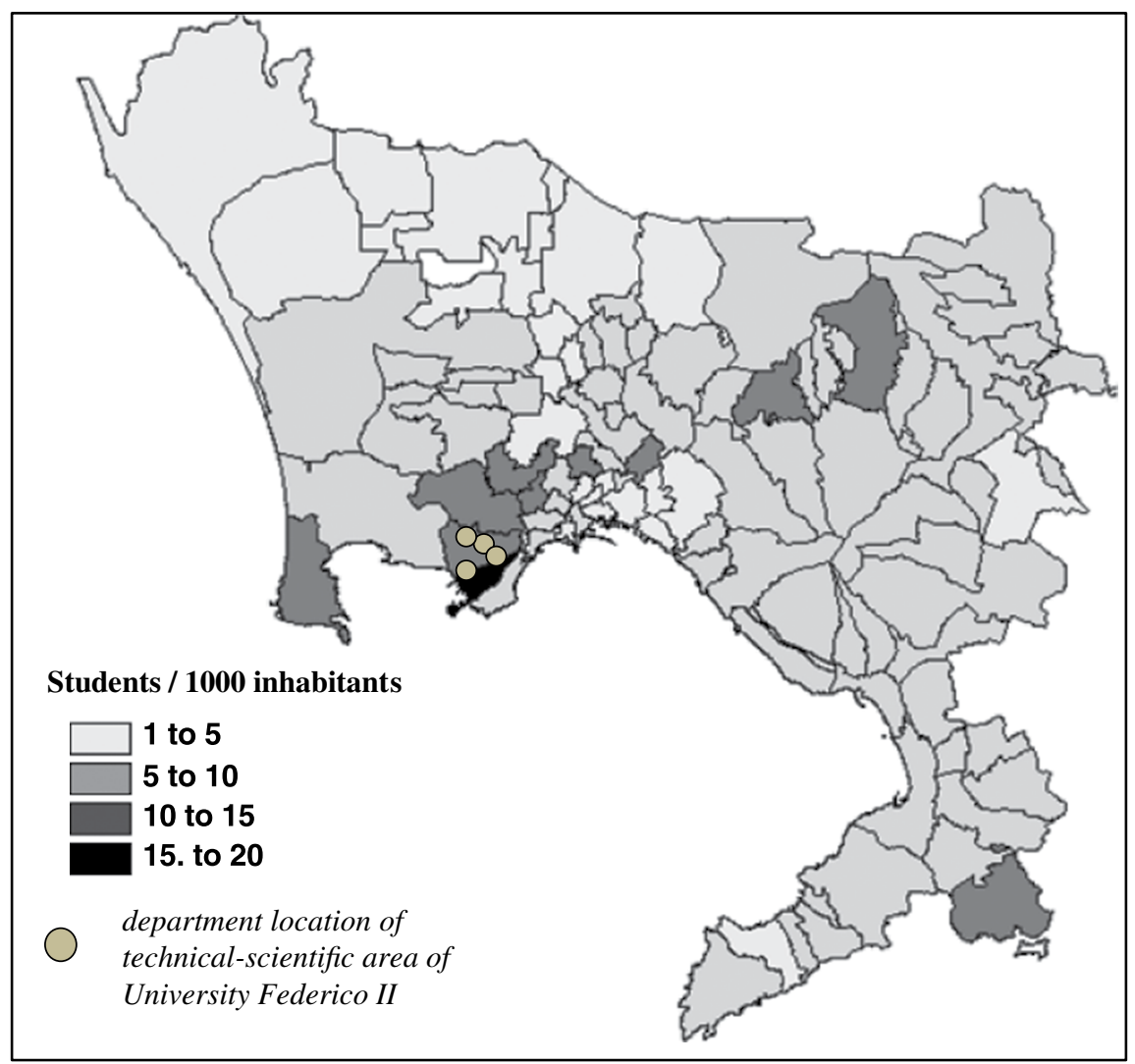

Figure 3: Rate of students (university students/1,000 inhabitants) of the technical and scientific departments of the University of Naples Federico II.

Considering the data about zoning used in Fig. 3, a cumulative distribution of students/ inhabitants based on the distances $(\mathrm{km})$ is estimated (Fig. 4). The comparison of two diagrams confirms the proximity effect as introduced earlier. For example, $87 \%$ of students live within a distance of $50 \mathrm{~km}$ from the departments analysed against the $68 \%$ of inhabitants.

The geographic distribution of students' residences is also analysed based on the distance from the railway stations (railway accessibility). Figure 5 shows the railway lines that have a station near the university and the other metropolitan of Naples the Line 1. From Fig. 5 it could be observed that the rate of students is higher in areas that are served by rail service. Mostly $50 \%$ of the university students live within a distance shorter than $1.5 \mathrm{~km}$ from the railway station.

This result shows that the choice of university is influenced not only by proximity effect, but also by the distance between the students' residences and the railway station (railway accessibility).

\section{MODEL ESTIMATION}

From the geographical distribution of residences of the students who belong to the technical and scientific departments of the University of Naples (Campania, Italy) (described in the above paragraph "The Case Study"), it is determined that the choice of university is 

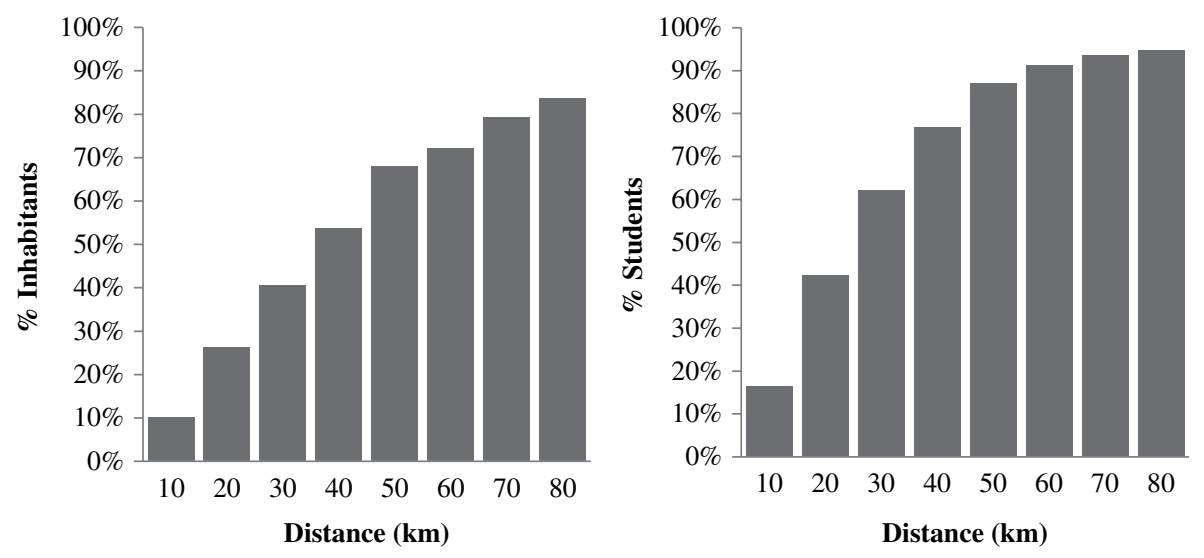

Figure 4: The cumulative distribution of distances $(\mathrm{km})$ between the technical and scientific departments of the university of Naples Federico II and the residence of inhabitants of Campania and enrolled students.

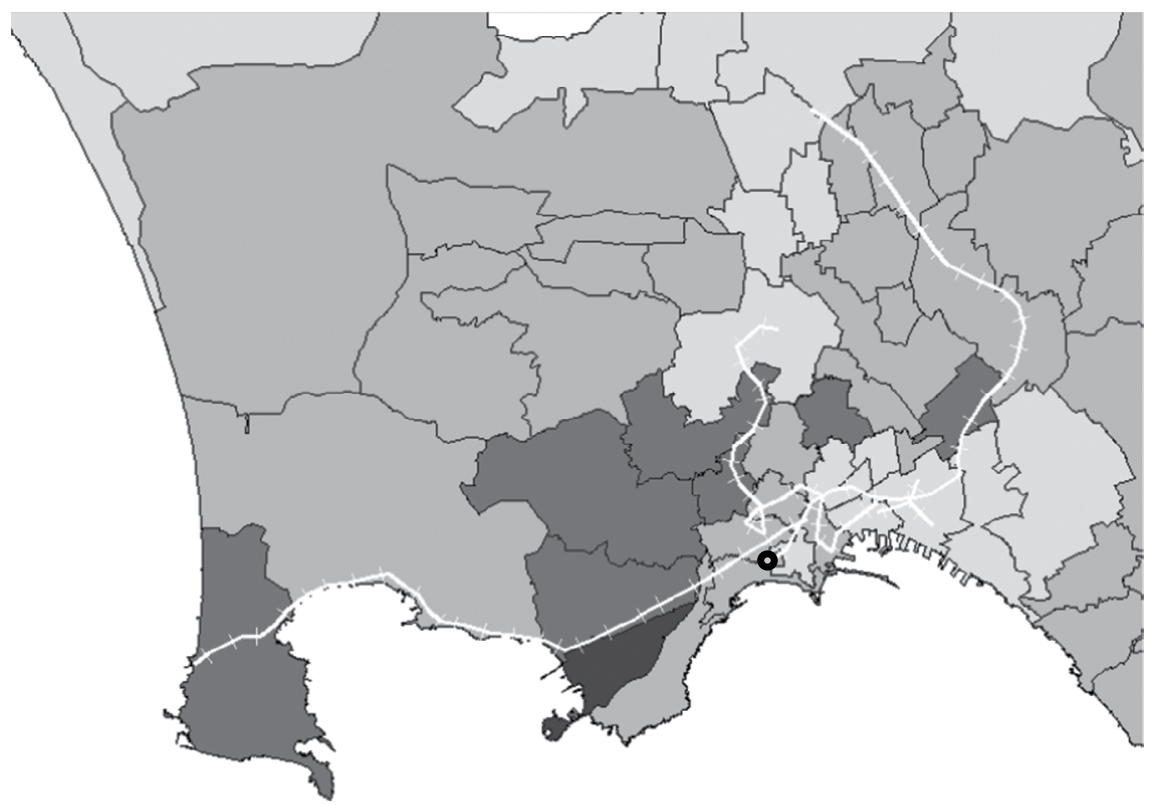

Station near department technical
scientific area of Federico II

Figure 5: The rate of students (university students/1000 inhabitants) of the technical and scientific departments of the University of Naples Federico II.

influenced by the distance between the students' residences and the university and by the distance between the students' residences and the railway station (transport accessibility). To estimate the effect of railway accessibility on the choice of university studies, a logistic regression model was used $[18,19]$.

Logistic regression measures the relationship between a dependent variable $(y)$ and one or more independent variables $\left(x_{i}\right)$ [18]. To estimate the probabilities, a logistic function, 
which is the cumulative logistic distribution, was used. The aim was to estimate the independent variable $\left(x_{i}\right)$ that influences the rate of students in different areas. The formula used to describe this phenomenon is as follows:

$$
y_{i}=\frac{1}{\left(1+\exp \left(\sum_{j}-x_{j} * \beta_{j}\right)\right)},
$$

where

$y_{i}$ is the rate students in the $i$ th zone.

$\mathrm{x}_{j}$ is the $j$ th parameter considered.

$\beta_{j}$ is the generic $j$ th parameter of the model.

Considering the zoning data described in Section 2 and through the Gretl software [20], different systematic utility functions were specified. Table 1 reports the best tested attributes and those that are statistically significant.

The attributes of the model that are statistically significant are the following:

- Distance ${ }_{\text {od }}(\mathrm{km})$ : it is measured considering the minimum path in street network between the university and the area where the residences are;

- Other university ${ }_{i}(1,0)$ : a Boolean variable that assumes value 1 if the residences are in the same zone where the other universities are (which are different from the technical and scientific departments discussed); it is 0 otherwise;

- Railway accessibility $(1,0)$ : a Boolean variable that assumes value 1 if the walking distance between the residences area and the railway station is less than $900 \mathrm{~m}$ (this threshold was estimated);

- Constant-specific alternative: it considers other phenomenon that influences the users' choice but has not been explicitly taken into account through the other variable.

The values estimated were compared to the result of other studies (e.g. [21-25]).

One of the most interesting results is related to the values of railway accessibility: comparing the value of parameters estimated in the model, it is observed that to travel from a station at a distance less than $900 \mathrm{~m}$ (subway) is equivalent (in terms of perceived utility) to travel every day a distance greater than $28 \mathrm{~km}$ to reach the university.

Table 1: Model estimation results.

\begin{tabular}{ll}
\hline Parameter & Model \\
\hline distance $_{\text {od }}[\mathrm{km}]$ & -0.01 \\
Std. Error/t-test & 0.01 to 2.60 \\
other university $[1,0]$ & -0.35 \\
Std. Error/t-test & 0.18 to 1.90 \\
railway accessibility $[1,0]$ & 0.28 \\
Std. Error/t-test & 0.17 to 1.67 \\
\hline
\end{tabular}




\section{CONCLUSION AND RESEARCH PERSPECTIVE}

The aim of this paper was to estimate the effect of railway accessibility on the choice of university studies through the following:

a. The analysis of the geographical distribution of the residences of the students enrolled in the technical and scientific departments of the University of Naples Federico II.

b. The estimation, through a regression method, of the weight of a rail service attributes (railway accessibility) to the choice of university studies.

The geographic distribution of the students' residences shows that the students prefer to live in areas which are in close 'proximity' to the university. For example, $87 \%$ of students live within a distance of $50 \mathrm{~km}$ from the departments analysed against the $68 \%$ of inhabitants. In addition, mostly $50 \%$ of university students of the technical and scientific departments of the University of Naples Federico II travel a distance shorter than $1.5 \mathrm{~km}$ from the railway station. To evaluate the 'weight' of a specific railway accessibility attribute, a regression model was used. The result of the study shows the surprising role of railway accessibility in the choice of university studies: to travel to a station within $900 \mathrm{~m}$ from home is equivalent (in terms of perceived utility) to travel every day a distance greater than $28 \mathrm{~km}$ to reach the university.

This result shows that the public transport, and in particular the railway transport, influences not only the attendance of students for university activities, but also the choice of students in deciding which university to choose for their education.

The research prospective is to also consider the level of attributes of the railway services in the choice model (e.g. time ${ }_{\text {od }}$, cost $_{\text {od }}$ ). In this way, the proposed model could be applied within the optimization planning procedures (e.g. [26]) in case of unexpected events too (e.g. [27, 28]).

The research prospects will include the following:

- extending this analysis to all departments of the University of Naples Federico II;

- evaluating the attributes that influence the choice of university studies (in particular, the 'weight' of specific attributes and the level of service of public transport) and discovering a discrete choice model.

\section{REFERENCES}

[1] Cascetta, E., Cartenì, A., Pagliara F. \& Montanino, M., A new look at planning and designing transportation systems: a decision-making model based on cognitive rationality, stakeholder engagement and quantitative methods. Transport Policy, 38, pp. 27-39, 2015. DOI: 10.1016/j.tranpol.2014.11.005.

[2] Cartenì, A., Urban sustainable mobility. Part 1: Rationality in transport planning. Transport Problems, 9(4), pp. 39-48, 2014.

[3] de Luca, S., Public engagement in strategic transportation planning: An analytic hierarchy process based approach. Transport Policy, 33, pp. 110-124, 2014.DOI: 10.1016/j. tranpol.2014.03.002.

[4] Hansen, W.G., How accessibility shapes land-use. Journal of the American Institute of Planners, 25, pp. 73-76, 1959. DOI: 10.1080/01944365908978307.

[5] Leonardi, G., Optimum facility location by accessibility maximizing. Environment and Planning A, 10, pp. 1287-305, 1978. DOI: 10.1068/a101287. 
[6] Cartenì, A., Accessibility indicators for freight transport terminals. Arabian Journal for Science and Engineering, 39, pp. 7647-7660, 2014.DOI: 10.1007/s13369-014-1333-y.

[7] Cartenì, A., Galante G. \& Henke I., The catchment area of high architectural railway stations: An application of the Graham scan algorithm. WIT Transactions on the Built Environment, 135, pp. 463-474, 2014. DOI: 10.2495/CR140381.

[8] Cascetta, E., Cartenì, A. \& Montanino, M., A behavioral model of accessibility based on the number of available opportunities. Journal of Transport Geography, 51, pp. 45-58, 2016. DOI: 10.1016/j.jtrangeo.2015.11.002.

[9] Politecnico di Milano, Mobility Management per il sistema universitario milanese, 2007. http://progetti.unicatt.it/. Accessed September 2014.

[10] Università degli Studi di Pavia, Gli spostamenti casa-università degli studenti dell'Università degli Studi di Pavia, 2014. http://www-wp.unipv.it/. Accessed May 2015.

[11] Horstschraer, J., University rankings in action? The importance of rankings and an excellence competition for university choice of high-ability students. Economics of Education Review, 31, pp. 1162-1176, 2012.

[12] Gürsesa, A., Büsra, K., Mindivana, F., Dogarb, Ç., Günes, K. \& Yolcua H.H., Determining the relationship between students' choice of profession and mission and vision of their high school. Procedia Social and Behavioral Sciences, 15, pp. 2595-2598, 2011. DOI: 10.1016/j.sbspro.2011.04.149.

[13] Cascetta, E. \& Cartenì, A., The hedonic value of railways terminals. A quantitative analysis of the impact of stations quality on travellers behaviour. Transportation Research Part A, 61, pp. 41-52, 2014.

[14] Cascetta, E. \& Cartenì, A., A quality-based approach to public transportation planning: theory and a case study. International Journal of Sustainable Transportation, 8(1), pp. 84-106, 2014.

[15] Cascetta E., Cartenì, A. \& Henke I., Stations quality, aesthetics and attractiveness of rail transport: empirical evidence and mathematical models [Qualità delle stazioni, estetica $e$ attrattività del trasporto ferroviario: evidenze empiriche e modelli matematici], Ingegneria Ferroviaria, 69(4), pp. 307-324, 2014.

[16] Cartenì, A., Galante G. \& Henke I., An assessment of models accuracy in predicting railways traffic flows: a before and after study in Naples. WIT Transactions on Ecology and the Environment, 191, pp. 783-794, 2014. DOI: 10.2495/SC140661.

[17] VI Rapporto dell'European Migration Network (Emn) Italia, Gli studenti internazionali nelle università italiane: indagine empirica e approfondimenti, http://www.yallaitalia. it, 2013. Accessed September 2014.

[18] Hosmer, D.W., Taber, S. \& Lemeshow, S., The importance of assessing the fit of logistic regression models: a case study. American Journal of Public Health, 81(12), pp. 1630-1635, December 1991. DOI: 10.2105/AJPH.81.12.1630.

[19] Hilbe, J.M., Logistic regression models, CRC Press, 2009.

[20] Battaglia, F., Metodi di previsione statistica, Collana di Statistica e Probabilità Applicata, Springer Science \& Business Media, 2010.

[21] de Luca, S. \& Cartenì, A., A multi-scale modelling architecture for estimating of transport mode choice induced by a new railway connection: The Salerno-University of Salerno-Mercato San Severino Route [Un'architettura modellistica multi-scala per la stima delle ripartizioni modali indotte da un nuovo collegamento ferroviario: il caso studio della tratta Salerno-Università di Salerno-Mercato San Severino]. Ingegneria Ferroviaria, 68 (5), pp. 447-473, 2013. 
[22] Cartenì, A., Updating demand vectors using traffic counts on congested networks: A real case application. WIT Transactions on the Built Environment, 96, pp. 211-221, 2007. DOI: $10.2495 /$ UT070211.

[23] Cartenì, A. \& Punzo, V., Travel time cost functions for urban roads: A case study in Italy. WIT Transactions on the Built Environment, 96, pp. 233-243, 2007. DOI: 10.2495/ UT070231.

[24] de Luca, S. \& Cantarella, G.E., Validation and comparison of choice models. Travel Demand Management and Road User Pricing: Success, Failure and Feasibility. New Delhi, India: Taylor \& Francis, pp. 37-58, 2009.

[25] De Luca, S. \& Papola, A., Evaluation of travel demand management policies in the urban area of Naples. Advances in Transport, 8, pp. 185-194, 2001.

[26] Montella, B., D'Acierno, L. \& Gallo, M., A multimodal approach for determining optimal public transport fares. Journal of Applied Sciences, 14(21), pp. 2767-2781, 2014. DOI: 10.3923/jas.2014.2767.2781.

[27] D'Acierno, L., Placido, A., Botte, M. \& Montella, B., A methodological approach for managing rail disruptions with different perspectives. International Journal of Mathematical Models and Methods in Applied Sciences, 10, pp. 80-86, 2016.

[28] D'Acierno, L., Gallo, M., Montella, B. \& Placido, A., The definition of a model framework for managing rail systems in the case of breakdowns. Proceedings of IEEE ITSC 2013 - 16th International IEEE Annual Conference on Intelligent Transportation Systems, The Hague, The Netherlands, pp. 1059-1064, 2013. 